\title{
Nomogram for prediction of fatal outcome in patients with severe COVID-19: a multicenter study
}

Yun Yang ${ }^{1,2+}$, Xiao-Fei Zhu ${ }^{2,3+}$, Jian Huang ${ }^{1+}$, Cui Chen ${ }^{1,2+}$, Yang Zheng ${ }^{4,5}$, Wei He $e^{6,7}$, Ling-Hao Zhao ${ }^{1,7}$, Qian Gao ${ }^{1,2}$, Xuan-Xuan Huang ${ }^{1,2}$, Li-Juan Fu' ${ }^{1,2}$, Yu Zhang ${ }^{1,2}$, Yan-Qin Chang ${ }^{1,7^{*}}$, Huo-Jun Zhang ${ }^{3^{*}}$ and Zhi-Jie Lu L $^{12^{*}}$

\begin{abstract}
Background: To develop an effective model of predicting fatal outcomes in the severe coronavirus disease 2019 (COVID-19) patients.

Methods: Between February 20, 2020 and April 4, 2020, consecutive confirmed 2541 COVID-19 patients from three designated hospitals were enrolled in this study. All patients received chest computed tomography (CT) and serological examinations at admission. Laboratory tests included routine blood tests, liver function, renal function, coagulation profile, C-reactive protein (CRP), procalcitonin (PCT), interleukin-6 (IL-6), and arterial blood gas. The $\mathrm{SaO}_{2}$ was measured using pulse oxygen saturation in room air at resting status. Independent high-risk factors associated with death were analyzed using Cox proportional hazard model. A prognostic nomogram was constructed to predict the survival of severe COVID-19 patients.

Results: There were 124 severe patients in the training cohort, and there were 71 and 76 severe patients in the two independent validation cohorts, respectively. Multivariate Cox analysis indicated that age $\geq 70$ years ( $H R=1.184$, 95\% Cl 1.061-1.321), panting (breathing rate $\geq 30 / \mathrm{min})(H R=3.300,95 \% \mathrm{Cl} 2.509-6.286)$, lymphocyte count $<1.0 \times$ $10^{9} / \mathrm{L}(H R=2.283,95 \% \mathrm{Cl} 1.779-3.267)$, and interleukin-6 (IL-6) > $10 \mathrm{pg} / \mathrm{ml}(H R=3.029,95 \% \mathrm{Cl} 1.567-7.116)$ were independent high-risk factors associated with fatal outcome. We developed the nomogram for identifying survival of severe COVID-19 patients in the training cohort (AUC $=0.900,95 \% \mathrm{Cl} 0.841-0.960$, sensitivity $95.5 \%$, specificity $77.5 \%$ ); in validation cohort 1 ( $\mathrm{UUC}=0.811,95 \% \mathrm{Cl} 0.763-0.961$, sensitivity $77.3 \%$, specificity $73.5 \%$ ); in validation cohort 2 ( $A \cup C=0.862,95 \% \mathrm{Cl} 0.698-0.924$, sensitivity $92.9 \%$, specificity $64.5 \%$ ). The calibration curve for probability of death indicated a good consistence between prediction by the nomogram and the actual observation. The prognosis of severe COVID-19 patients with high levels of IL-6 receiving tocilizumab were better than that of those patients without tocilizumab both in the training and validation cohorts, but without difference $(P=0.105$ for (Continued on next page)
\end{abstract}

\footnotetext{
*Correspondence: changyanqin1018@163.com; chyyzhj@163.com;

luzhijieehbh@126.com

${ }^{\dagger}$ Yun Yang, Xiao-Fei Zhu, Jian Huang and Cui Chen contributed equally to this work.

${ }^{1}$ The Third Affiliated Hospital of Second Military Medical University, 225 Changhai Road, Shanghai 200438, China

${ }^{3}$ The First Affiliated Hospital of Second Military Medical University, Shanghai 200438, China

Full list of author information is available at the end of the article
}

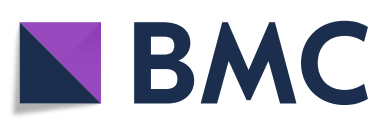

(c) The Author(s). 2021 Open Access This article is licensed under a Creative Commons Attribution 4.0 International License, which permits use, sharing, adaptation, distribution and reproduction in any medium or format, as long as you give appropriate credit to the original author(s) and the source, provide a link to the Creative Commons licence, and indicate if changes were made. The images or other third party material in this article are included in the article's Creative Commons licence, unless indicated otherwise in a credit line to the material. If material is not included in the article's Creative Commons licence and your intended use is not permitted by statutory regulation or exceeds the permitted use, you will need to obtain permission directly from the copyright holder. To view a copy of this licence, visit http://creativecommons.org/licenses/by/4.0/ The Creative Commons Public Domain Dedication waiver (http://creativecommons.org/publicdomain/zero/1.0/) applies to the data made available in this article, unless otherwise stated in a credit line to the data. 
(Continued from previous page)

training cohort, $P=0.133$ for validation cohort 1 , and $P=0.210$ for validation cohort 2).

Conclusions: This nomogram could help clinicians to identify severe patients who have high risk of death, and to develop more appropriate treatment strategies to reduce the mortality of severe patients. Tocilizumab may improve the prognosis of severe COVID-19 patients with high levels of IL-6.

Keywords: Severe COVID-19, Nomogram, Prediction, Survival

\section{Background}

Previous studies have indicated that in all coronavirus disease 2019 (COVID-19) patients, the incidence of severe cases is approximately $15 \%[1,2]$. The mortality rate of severe COVID-19 patients varies from 8.0 to $61.5 \%$ and significantly increases among older patients [3-8]. Early medical intervention is very important to reduce the mortality of severe patients. Thus, it is of great importance to screen out severe patients with a high risk of death promptly and accurately at the initial admission [9]. However, this is particularly difficult because of limited medical resources and staff and the large number of patients. Therefore, elucidating the independent risk factors and establishing an accurate model for predicting severe COVID-19 patients at high risk of death is necessary.

A previously established nomogram suggested five prognostic factors for predicting the outcome: Acute Physiology and Chronic Health Evaluation II (APACHE II), creatine kinase (CK), C-reactive protein (CRP), immunoglobulin A (IgA), and the interaction between CK and APACHE II [10]. However, risk factors associated with fatal outcomes in severe patients are unclear. This study aimed to provide a model to help clinicians identify patients with severe COVID-19 at high risk of death, which may be beneficial for decision making regarding treatment strategies.

\section{Methods}

\section{Study population}

Between February 20, 2020 and April 4, 2020, consecutive confirmed COVID-19 patients were assessed to enter into this study from three designated hospitals of COVID-19 in China: the Guanggu Branch of the Women and Children's Hospital of Hubei Province, Tongji Taikang Hospital and Huoshen Mountain Hospital. The diagnosis of COVID-19 was based on the World Health Organization (WHO) interim guidance and guidelines for diagnosis and treatment of novel coronavirus pneumonia $\left(5^{\text {th }}\right.$ version) released by the $\mathrm{Na}$ tional Health Commission of China [11, 12]. The presence of severe acute respiratory syndrome coronavirus 2 (SARS-CoV-2) in respiratory specimens was confirmed by a positive result of quantitative real-time reverse transcriptase-polymerase chain reaction (qRT-
PCR) assay from nasal or pharyngeal swab specimens. Swab samples were collected and tested for SARS-CoV2 with the Chinese Center for Disease Control and Prevention (CDC) recommended Kit (BioGerm, Shanghai, China), following WHO guidelines for qRT-PCR [1315]. All samples were tested for SARS-CoV-2 by use of qRT-PCR with the CDC recommended Kit. The test results were confirmed by nested RT-PCR with designed primers. The nested RT-PCR assay was performed according to the previous report [16].

Severe COVID-19 group was defined if meeting at least one of the following criteria: (1) Shortness of breath, breathing rate $\geq 30 / \mathrm{min}$, (2) Arterial oxygen saturation $\left(\mathrm{SaO}_{2}\right.$, resting status $\leq 93 \%$, or (3) the ratio of partial pressure of arterial oxygen $\left(\mathrm{PaO}_{2}\right)$ to fraction of inspired oxygen $\left(\mathrm{FiO}_{2}\right) \leq 300 \mathrm{mmHg}$.

During the study period, a total of 2541 patients were enrolled into this study. Of 2541 cases included in this study, 1056 patients were from the Guanggu Branch of the Women and Children's Hospital of Hubei Province, 726 were from Tongji Taikang Hospital, and 759 were from Huoshen Mountain Hospital. According to the definition of severe COVID-19 described above, there were 124,71 , and 76 severe cases from the three hospitals, respectively. Therefore, 124 patients with severe diseases from the Guanggu Branch of the Women and Children's Hospital of Hubei Province were included in the training cohort, while 71 and 76 severe cases in other two hospitals formed validation cohort. The selection of the study population was shown in Supplemental Fig. 1. The study was approved by the Ethics Committee of all centers. Written informed consent was waived by the Ethics Commission of each hospital for emerging infections.

\section{Data collection}

All patients received chest computed tomography $(\mathrm{CT})$ and serological examinations at admission. Laboratory tests included routine blood tests, liver function, renal function, coagulation profile, CRP, procalcitonin (PCT), interleukin-6 (IL-6), and arterial blood gas. The $\mathrm{SaO}_{2}$ was measured using pulse oxygen saturation in room air at resting status. Comorbidity was defined as having at least one of the followings: Hypertension, diabetes, cardiovascular disease, cerebrovascular disease, chronic lung disease, and malignant tumor for at least 6 months. 
All data were collected, re-checked for accuracy independently by at least two researchers.

\section{Statistical analysis}

Continuous variables were expressed as mean (SD). Categorical variables were expressed as frequency (percentage). Categorical variables were compared by the $\chi^{2}$ test or Fisher's exact test. Continuous variables were compared by the Student's $t$ test or Mann-Whitney $U$ test. Survival curves were analyzed using the Kaplan-Meier method. Differences between curves were assessed using the Log-rank test.

Univariate and multivariate Cox proportional regression analysis was used for investigating the independent risk factors of death. The independent risk factors associated with the risk of mortality of patients with severe COVID-19 were used to build the nomogram in the training cohort. The performance and accuracy of the established nomogram were assessed by receiver operating characteristic (ROC) curve and calibration with 1000 bootstrap samples. The area under ROC (AUC) and optimal cut-off values were determined. Decision curve analysis (DCA) based on the net benefit was depicted by the package of Rmda in R. The nomogram was validated in the validation cohorts 1 and 2 , respectively. The nomogram was constructed and evaluated using the $\mathrm{R}$ software version 3.4.1 package with the Rms and Hmisc. All statistical analysis was performed using $\mathrm{R}$ version 3.4.1, a $P<0.05$ in two-tailed was the significance threshold.

\section{Results}

\section{Patient clinical characteristics}

Of 2541 patients included in this study, 271 patients had severe COVID-19 and 2270 were non-severe cases. Supplemental Table 1 indicated the basic characteristics of the study cohorts. Compared with non-severe cases, patients were older $(P<0.001)$ and more males $(P<0.001)$ were found in the severe disease cohort. In addition, there is more comorbidity in severe cases $(P<0.001)$. The proportion of patients with panting was higher in the severe cases $(P<0.001)$. Higher levels of white blood cell (WBC) count, neutrophil count, CRP, PCT, IL-6, total bilirubin (TBIL), alanine aminotransferase (ALT), aspartate aminotransferase (AST), lactate dehydrogenase (LDH), $\gamma$-glutamyl transpeptidase $(\gamma-\mathrm{GT})$, and creatinine $(\mathrm{Cr})$ were identified in severe cases $(P<0.001)$, while the levels of lymphocyte count, platelet (PLT), and $\mathrm{SaO}_{2}$ of patients with severe disease were lower than those in non-severe cases $(P<0.001)$. There were 186 patients with no manifestations of chest $\mathrm{CT}$ in non-severe COVID-19 cohort, and no significant differences of the findings of chest $\mathrm{CT}$ between severe and non-severe cases were found $(P>0.05)$. By the end of April 4, 2020, there were 58 and 39 patients died in the severe and non-severe disease group, respectively (Supplemental Table 1).

The basic characteristics of the severe patients are listed in Supplemental Table 2. The median age of the patients was 68 (range 20-100) years. One hundred and fifty-two $(56.1 \%)$ patients were males and there were one hundred nineteen $(43.9 \%)$ female patients. There were $73(26.9 \%)$ patients who had a high WBC count of > $10 \times 10^{9} / \mathrm{L}$, and $148(54.6 \%)$ patients with lymphopenia defined as lymphocyte count of $\leq 1.0 \times 10^{9} / \mathrm{L}$. Ninety-five (35.1\%) patients had a high neutrophil count of $>6.3 \times$ $10^{9} / \mathrm{L}$, while $26(9.6 \%)$ patients had a low PLT count of $<100 \times 10^{9} / \mathrm{L}$. Ground-glass opacity and consolidation were found in $122(45.0 \%)$ and $114(42.1 \%)$ patients, respectively. In addition, twenty-eight (10.3\%) and seven (2.6\%) patients had thickened interlobular septa and nodular lesions, respectively in chest CT. Of 271 severe patients, 58 died during the study period (Supplemental Table 2).

Comparison of baseline characteristics between patients in training and validation cohorts can be seen in Table 1. There were significant differences of age, proportion of smokers, incidence of panting, WBC, neutrophil count, CRP and $\mathrm{SaO}_{2}$ at admission between the three cohorts $(P<0.05)$. There was no significant difference in the other variables between the three cohorts $(P>0.05)$. By the end of April 4, 2020, 22 severe COVID-19 patients died in the training group, and 22 and 14 patients died in the validation group 1 and validation group 2 , respectively (Table 1 ).

The baseline characteristics of patients in the training cohort were shown in Table 2. There were no significant differences in gender, TBIL, ALT, AST, LDH, $\gamma$-GT, Cr, PLT, and the proportion of smokers between survivors and non-survivors $(P>0.05)$. Survivors were significantly younger than the non-survivors in the training cohort $[(70.4 \pm 12.3)$ years $v s .(81.6 \pm 7.3)$ years, $P<0.05]$, however, the proportion of patients with multiple comorbidities and panting (breathing rate $\geq 30 / \mathrm{min}$ ) was significantly higher in non-survivors $(P<0.05)$. In addition, WBC and neutrophil count, CRP, D-dimer, PCT, and IL-6 were also significantly higher in nonsurvivors $(P<0.05)$. The lymphocyte count was significantly lower in non-survivors $(P<0.05)$.

\section{Independent high-risk factors associated with the fatal outcome}

All variables listed in Table 1 were analyzed by univariate and multivariate Cox regression analysis. Multivariate Cox analysis indicated that age $\geq 70$ years $(H R=$ $1.184,95 \%$ CI 1.061-1.321), panting (breathing rate $\geq$ 30/min, $H R=3.300,95 \%$ CI 2.509-6.286), lymphocyte count $<1.0 \times 10^{9} / \mathrm{L}(H R=2.283,95 \%$ CI $1.779-3.267)$, 
Table 1 Comparison of baseline characteristics between patients in training and validation cohorts [ $n(\%)]$

\begin{tabular}{|c|c|c|c|c|}
\hline Variables & Training cohort $(n=124)$ & Validation cohort $1(n=71)$ & Validation cohort $2(n=76)$ & $P$ \\
\hline Age (year) & & & & 0.001 \\
\hline$\geq 70$ & $73(58.9)$ & $25(35.2)$ & $29(38.2)$ & \\
\hline$<70$ & $51(41.1)$ & $46(64.8)$ & $47(61.8)$ & \\
\hline \multicolumn{5}{|l|}{ Gender } \\
\hline Male & $69(55.7)$ & $42(59.2)$ & $41(54.0)$ & 0.810 \\
\hline Comorbidity & & & & 0.291 \\
\hline Without comorbidity & $31(25.0)$ & $27(38.0)$ & $26(34.2)$ & \\
\hline With single comorbidity & $38(30.7)$ & $16(22.6)$ & $21(27.6)$ & \\
\hline With multiple comorbidity & $55(44.3)$ & $28(39.4)$ & $29(38.2)$ & \\
\hline Smoke & $66(53.2)$ & $16(22.5)$ & $19(25.0)$ & $<0.001$ \\
\hline Panting (breathing rate $\geq 30 / \mathrm{min}$ ) & $56(45.2)$ & $63(88.7)$ & $67(88.2)$ & $<0.001$ \\
\hline WBC $\left(\times 10^{9} / \mathrm{L}\right)$ & & & & 0.005 \\
\hline$>10$ & $24(19.4)$ & $29(40.9)$ & $20(26.3)$ & \\
\hline$\leq 10$ & $100(80.6)$ & $42(59.1)$ & $56(73.7)$ & \\
\hline Lymphocyte $\left(\times 10^{9} / \mathrm{L}\right)$ & & & & 0.352 \\
\hline$>1.0$ & $56(45.2)$ & $28(39.4)$ & 39 (51.3) & \\
\hline$\leq 1.0$ & $68(54.8)$ & $43(60.6)$ & $37(48.7)$ & \\
\hline Neutrophil $\left(\times 10^{9} / L\right)$ & & & & 0.013 \\
\hline$>6.3$ & $36(29.0)$ & $35(49.3)$ & 24 (31.6) & \\
\hline$\leq 6.3$ & $88(71.0)$ & $36(50.7)$ & $52(68.4)$ & \\
\hline $\operatorname{PLT}\left(\times 10^{9} / \mathrm{L}\right)$ & & & & 0.346 \\
\hline$\geq 100$ & $114(91.9)$ & $61(85.9)$ & $70(92.1)$ & \\
\hline$<100$ & $10(8.1)$ & $10(14.1)$ & $6(7.9)$ & \\
\hline CRP (mg/L) & & & & 0.026 \\
\hline$>10$ & $70(56.5)$ & $36(50.7)$ & $28(36.8)$ & \\
\hline$\leq 10$ & $54(43.5)$ & $35(49.3)$ & $48(63.2)$ & \\
\hline D-dimer (mg/L) & & & & 0.992 \\
\hline$>0.55$ & $81(65.3)$ & $46(64.8)$ & $50(65.8)$ & \\
\hline$\leq 0.55$ & $43(34.7)$ & $25(35.2)$ & $26(34.2)$ & \\
\hline PCT (ng/ml) & & & & 0.312 \\
\hline$>0.05$ & $87(70.2)$ & $57(80.3)$ & $56(73.7)$ & \\
\hline$\leq 0.05$ & 37 (29.8) & $14(19.7)$ & $20(26.3)$ & \\
\hline IL-6 (pg/ml) & & & & 0.298 \\
\hline$\geq 10$ & $68(54.8)$ & $47(66.2)$ & $44(57.9)$ & \\
\hline$<10$ & $56(45.2)$ & $24(33.8)$ & $32(42.1)$ & \\
\hline $\mathrm{SaO}_{2}$ on admission & & & & $<0.001$ \\
\hline$\geq 90 \%$ & 85 (68.6) & $18(25.4)$ & $34(44.7)$ & \\
\hline$<90 \%$ & $39(31.4)$ & $53(74.6)$ & $42(55.3)$ & \\
\hline TBIL $(\mu \mathrm{mol} / \mathrm{L})$ & & & & 0.098 \\
\hline$\geq 20$ & $45(36.3)$ & $16(22.5)$ & $28(36.8)$ & \\
\hline$<20$ & $79(63.7)$ & $55(77.5)$ & $48(63.2)$ & \\
\hline $\operatorname{ALT}(U / L)$ & & & & 0.363 \\
\hline$\geq 40$ & $35(28.2)$ & $22(31.0)$ & $16(21.1)$ & \\
\hline$<40$ & 89 (71.8) & $49(69.0)$ & $60(78.9)$ & \\
\hline
\end{tabular}


Table 1 Comparison of baseline characteristics between patients in training and validation cohorts [ $(\%)$ ] (Continued)

\begin{tabular}{|c|c|c|c|c|}
\hline Variables & Training cohort $(n=124)$ & Validation cohort $1(n=71)$ & Validation cohort $2(n=76)$ & $P$ \\
\hline AST (U/L) & & & & 0.633 \\
\hline$\geq 40$ & $41(33.1)$ & $19(26.8)$ & $25(32.9)$ & \\
\hline$<40$ & $83(66.9)$ & $52(73.2)$ & $51(67.1)$ & \\
\hline $\mathrm{LDH}(\mathrm{U} / \mathrm{L})$ & & & & 0.341 \\
\hline$\geq 245$ & $36(29.0)$ & $26(36.6)$ & $29(38.2)$ & \\
\hline$<245$ & $88(71.0)$ & $45(63.4)$ & $47(61.8)$ & \\
\hline$\gamma-G T(U / L)$ & & & & 0.262 \\
\hline$\geq 50$ & $64(51.6)$ & $28(39.4)$ & $36(47.4)$ & \\
\hline$<50$ & $60(48.4)$ & $43(60.6)$ & $40(52.6)$ & \\
\hline $\mathrm{Cr}(\mu \mathrm{mol} / \mathrm{L})$ & & & & 0.303 \\
\hline$>80$ & $41(33.1)$ & $29(40.9)$ & $21(27.6)$ & \\
\hline$\leq 80$ & $83(66.9)$ & $42(59.1)$ & $55(72.4)$ & \\
\hline Outcomes & & & & 0.070 \\
\hline Dead & $22(17.7)$ & $22(31.0)$ & $14(18.4)$ & \\
\hline Alive & $102(82.3)$ & $49(69.0)$ & $62(81.6)$ & \\
\hline
\end{tabular}

WBC White blood cell, PLT Platelet, CRP C-reactive protein, PCT Procalcitonin, IL-6 Interleukin-6, $\mathrm{SaO}_{2}$ Oxygen saturation, TBIL Total bilirubin, ALT Alanine aminotransferase, AST Aspartate aminotransferase, LDH Lactate dehydrogenase, $\gamma$-GT $\gamma$-glutamyl transpeptadase, $\mathrm{Cr}$ Creatinine

and $\mathrm{IL}-6>10 \mathrm{pg} / \mathrm{ml}(H R=3.029,95 \%$ CI $1.567-7.116)$ were independent risk factors associated with fatal outcomes (Table 3).

\section{Survival analysis in the patients with the high level of IL-6} Due to the high level of IL-6 correlating with poor outcomes in severe COVID-19 patients, the therapeutic effect of tocilizumab in the patients with high IL-6 was further analyzed. In the training cohort, it was demonstrated that the prognosis of patients receiving tocilizumab was better than that of patients not receiving tocilizumab, but without significance $(P=0.105$, Supplemental Fig. 2a). Similar results were also observed in the validation cohort 1 and validation cohort 2 , respectively $(P=0.133, P=0.210$, Supplemental Fig. $2 \mathrm{~b}-\mathrm{c})$.

\section{Construction and validation of the nomogram}

Four independent risk factors found to be associated with the risk of mortality of patients in the multivariate analyses were incorporated into the nomogram (Fig. 1). The ROC curve was employed to assess the predictive ability of the established nomogram, and the result demonstrated that the AUC was 0.900 (95\% CI 0.841-0.960) in the training cohort, with a sensitivity of $95.5 \%$ and specificity of $77.5 \%$ (Fig. 2a). Moreover, the calibration curves for nomogram predicted mortality indicated that a good consistency between observed actual outcomes and predicted ones in the training cohort (Fig. 3a).

In the validation cohort 1 , the AUC was 0.811 (95\% CI $0.763-0.961$ ) for patients with a sensitivity of $77.3 \%$ and specificity of $73.5 \%$ (Fig. $2 \mathrm{~b}$ ). In the validation cohort 2 , the AUC was 0.862 (95\% CI $0.698-0.924)$ for patients with a sensitivity of $92.9 \%$ and specificity of $64.5 \%$ (Fig. 2c). The calibration curves also showed good agreement between prediction and observation in the risk of mortality in the two validation cohorts (Fig. 3b-c).

\section{Clinical application of the nomogram}

DCA based on the net benefit and threshold probabilities was performed to assess the clinical applicability of the risk prediction nomogram. The DCA showed that our risk prediction nomogram had a superior net benefit with a wide range of threshold probabilities in the training cohort and validation cohorts (Fig. 4).

\section{Discussion}

Our study revealed the clinical characteristics and risk factors for fatal outcomes in confirmed severe COVID19 patients based on multicenter cohorts. Multivariate Cox analysis in this study indicated that age, lymphopenia, respiratory rate $\geq 30 / \mathrm{min}$, and IL- 6 were independent high-risk factors associated with poor prognosis. Older age has been proven to be a risk factor for the virus infection and survival in many previous studies [17-20]. Elderly patients with severe COVID-19 were more likely to develop fatal outcomes because of the rapid progression of the disease, which reminded us of providing early intervention for elderly severe patients. Similarly, lymphopenia was more common in the nonsurvivors and severe cases according to previous reports, suggesting dysregulation of the immune response in patients with COVID-19 [21-23]. Nevertheless, most of these were only descriptive studies. A study clarified that lower lymphocyte count was predictive of COVID-19 
Table 2 Baseline characteristics of patients in the training cohort [ $n(\%)]$

\begin{tabular}{|c|c|c|c|}
\hline Variables & Death $(n=22)$ & Discharge $(n=102)$ & $P$ \\
\hline \multicolumn{4}{|l|}{ Gender } \\
\hline Male & $14(63.6)$ & $55(53.9)$ & 0.407 \\
\hline Comorbidity & & & 0.005 \\
\hline Without comorbidity & $1(4.6)$ & $30(29.4)$ & \\
\hline With single comorbidity & $6(27.3)$ & $32(31.4)$ & \\
\hline With multiple comorbidity & $15(68.1)$ & $40(39.2)$ & \\
\hline Smoke & $13(59.1)$ & $53(52.0)$ & 0.545 \\
\hline Panting (breathing rate $\geq 30 / \mathrm{min}$ ) & $17(77.3)$ & $39(38.2)$ & 0.001 \\
\hline WBC $\left(\times 10^{9} / \mathrm{L}\right)$ & & & 0.001 \\
\hline$>10$ & $10(45.5)$ & $14(13.7)$ & \\
\hline$\leq 10$ & $12(54.5)$ & $88(86.3)$ & \\
\hline Lymphocyte $\left(\times 10^{9} / \mathrm{L}\right)$ & & & $<0.001$ \\
\hline$>1.0$ & $2(9.1)$ & $54(52.9)$ & \\
\hline$\leq 1.0$ & $20(90.9)$ & $48(47.1)$ & \\
\hline Neutrophil $\left(\times 10^{9} / \mathrm{L}\right)$ & & & 0.001 \\
\hline$>6.3$ & $13(59.1)$ & $23(22.6)$ & \\
\hline$\leq 6.3$ & $9(40.9)$ & $79(77.4)$ & \\
\hline $\operatorname{PLT}\left(\times 10^{9} / \mathrm{L}\right)$ & & & 0.076 \\
\hline$\geq 100$ & $18(81.8)$ & $96(94.1)$ & \\
\hline$<100$ & $4(18.2)$ & $6(5.9)$ & \\
\hline CRP (mg/L) & & & 0.008 \\
\hline$>10$ & $18(81.8)$ & $52(51.0)$ & \\
\hline$\leq 10$ & $4(18.2)$ & $50(49.0)$ & \\
\hline D-dimer (mg/L) & & & 0.006 \\
\hline$>0.55$ & $20(90.9)$ & $61(59.8)$ & \\
\hline$\leq 0.55$ & $2(9.1)$ & $41(40.2)$ & \\
\hline PCT (ng/ml) & & & 0.020 \\
\hline$>0.05$ & $20(90.9)$ & $67(65.7)$ & \\
\hline$\leq 0.05$ & $2(9.1)$ & $35(34.3)$ & \\
\hline IL-6 (pg/ml) & & & $<0.001$ \\
\hline$\geq 10$ & $21(95.5)$ & $47(46.1)$ & \\
\hline$<10$ & $1(4.5)$ & $55(53.9)$ & \\
\hline $\mathrm{SaO}_{2}$ on admission & & & 0.294 \\
\hline$\geq 90 \%$ & $13(59.1)$ & $72(70.6)$ & \\
\hline$<90 \%$ & $9(40.9)$ & $30(29.4)$ & \\
\hline TBIL $(\mu \mathrm{mol} / \mathrm{L})$ & & & 0.326 \\
\hline$\geq 20$ & $10(45.5)$ & $35(34.3)$ & \\
\hline$<20$ & $12(54.5)$ & $67(65.7)$ & \\
\hline $\operatorname{ALT}(U / L)$ & & & 0.147 \\
\hline$\geq 40$ & $9(40.9)$ & $26(25.5)$ & \\
\hline$<40$ & $13(59.1)$ & $76(74.5)$ & \\
\hline AST (U/L) & & & 0.213 \\
\hline$\geq 40$ & $10(45.5)$ & $31(30.4)$ & \\
\hline$<40$ & $12(54.5)$ & $71(69.6)$ & \\
\hline
\end{tabular}


Table 2 Baseline characteristics of patients in the training cohort [n(\%)] (Continued)

\begin{tabular}{lll}
\hline Variables & Death $(\boldsymbol{n = 2 2 )}$ & Discharge $(\boldsymbol{n}=\mathbf{1 0 2})$ \\
\hline $\begin{array}{l}\mathrm{LDH}(\mathrm{U} / \mathrm{L}) \\
\geq 245\end{array}$ & $14(63.6)$ & $75(73.5)$ \\
$\quad<245$ & $8(36.4)$ & $27(26.5)$ \\
$\mathrm{Y}-\mathrm{GT}(\mathrm{U} / \mathrm{L})$ & & \\
$\quad \geq 50$ & $13(59.1)$ & $51(50.0)$ \\
$\quad<50$ & $9(40.9)$ & $51(50.0)$ \\
$\mathrm{Cr}(\mu \mathrm{mol} / \mathrm{L})$ & & \\
$\quad>80$ & $8(36.4)$ & $33(32.4)$ \\
$\quad \leq 80$ & $14(63.6)$ & $69(67.6)$ \\
\hline
\end{tabular}

WBC White blood cell, PLT Platelet, CRP C-reactive protein, PCT Procalcitonin, IL-6 Interleukin- 6 , SaO 2 Oxygen saturation, TBIL Total bilirubin, ALT Alanine aminotransferase, AST Aspartate aminotransferase, $L D H$ Lactate dehydrogenase, $\gamma$-GT $\gamma$-glutamyl transpeptadase, $C r$ Creatinine

progression [24], whereas the impact of lymphocyte count on the survival of severe COVID-19 was unclear. This study demonstrated that a lymphocyte count < $1.0 \times 10^{9} / \mathrm{L}$ was independently associated with death in severe cases.
Recent studies have found that the cytokine storm is an important factor leading to rapid disease progression and poor prognosis $[25,26]$. IL- 6 is one of the major cytokines involved in cytokine storms [27, 28]. A previous univariate analysis showed that the IL-6 level was

Table 3 Univariate and multivariate COX proportional hazards regression analysis of death in the training cohort

\begin{tabular}{|c|c|c|c|c|}
\hline \multirow[t]{2}{*}{ Variable } & \multicolumn{2}{|l|}{ Univariate } & \multicolumn{2}{|l|}{ Multivariate } \\
\hline & $H R(95 \% \mathrm{Cl})$ & $P$ & $H R(95 \% \mathrm{Cl})$ & $P$ \\
\hline Age ( $\geq 70$ years $v s .<70$ years) & $9.245(2.054-11.624)$ & 0.004 & $1.184(1.061-1.321)$ & 0.003 \\
\hline Gender (male vs. female) & $1.495(0.577-3.874)$ & 0.407 & - & - \\
\hline Comorbidity & & & - & - \\
\hline Without comorbidity & 1 & & 1 & \\
\hline With single comorbidity & $3.625(0.639-4.503)$ & 0.120 & $1.810(0.794-2.585)$ & 0.551 \\
\hline With multiple comorbidity & $2.250(1.407-4.947)$ & 0.022 & $1.155(0.831-3.130)$ & 0.479 \\
\hline Smoke (yes vs. no) & $1.309(0.533-3.212)$ & 0.556 & - & - \\
\hline Panting (breathing rate $\geq 30 / \mathrm{min}$ ) (yes vs. no) & $5.492(2.876-7.078)$ & 0.002 & $3.300(2.509-6.286)$ & 0.004 \\
\hline WBC $\left(>10 \times 10^{9} / \mathrm{L}\right.$ vs. $\left.\leq 10 \times 10^{9} / \mathrm{L}\right)$ & $5.238(1.906-9.397)$ & 0.001 & $2.046(0.726-4.503)$ & 0.524 \\
\hline Lymphocyte $\left(<1.0 \times 10^{9} / \mathrm{L}\right.$ vs. $\left.\geq 1.0 \times 10^{9} / \mathrm{L}\right)$ & $5.263(2.513-9.615)$ & 0.002 & $2.283(1.779-3.267)$ & 0.011 \\
\hline Neutrophil $\left(>6.3 \times 10^{9} / \mathrm{L}\right.$ vs. $\left.\leq 6.3 \times 10^{9} / \mathrm{L}\right)$ & $4.961(1.884-8.068)$ & 0.001 & $2.439(0.717-3.768)$ & 0.392 \\
\hline $\operatorname{PLT}\left(\geq 100 \times 10^{9} / \mathrm{L}\right.$ vs. $\left.<100 \times 10^{9} / \mathrm{L}\right)$ & $3.556(0.911-6.876)$ & 0.068 & - & - \\
\hline $\mathrm{CRP}(>10 \mathrm{mg} / \mathrm{L}$ vs. $\leq 10 \mathrm{mg} / \mathrm{L})$ & $4.327(1.369-7.677)$ & 0.013 & $1.214(0.721-2.211)$ & 0.196 \\
\hline D-dimer (> $0.55 \mathrm{mg} / \mathrm{L}$ vs. $\leq 0.55 \mathrm{mg} / \mathrm{L})$ & $6.721(1.490-9.319)$ & 0.013 & $1.395(0.668-3.268)$ & 0.195 \\
\hline PCT (> $0.05 \mathrm{ng} / \mathrm{ml}$ vs. $\leq 0.05 \mathrm{ng} / \mathrm{ml})$ & $3.224(1.154-6.645)$ & 0.032 & $2.255(0.768-4.767)$ & 0.118 \\
\hline $\mathrm{IL}-6(>10 \mathrm{pg} / \mathrm{ml}$ vs. $\leq 10 \mathrm{pg} / \mathrm{ml})$ & $4.547(3.184-8.659)$ & 0.002 & $3.029(1.567-7.116)$ & 0.009 \\
\hline $\mathrm{SaO}_{2}$ on admission $(\geq 90 \%$ vs. $<90 \%)$ & $1.662(0.739-2.007)$ & 0.180 & - & - \\
\hline TBIL $(\geq 20 \mu \mathrm{mol} / \mathrm{L}$ vs. $<20 \mu \mathrm{mol} / \mathrm{L})$ & $1.595(0.627-2.057)$ & 0.327 & - & - \\
\hline ALT $(\geq 40 \mathrm{U} / \mathrm{L}$ vs. $<40 \mathrm{U} / \mathrm{L})$ & $2.024(0.775-5.283)$ & 0.150 & - & - \\
\hline AST $(\geq 40 \mathrm{U} / \mathrm{L}$ vs. $<40 \mathrm{U} / \mathrm{L})$ & 1.909 (0.746-4.883) & 0.177 & - & - \\
\hline $\mathrm{LDH}(\geq 245 \mathrm{U} / \mathrm{L}$ vs. $<245 \mathrm{U} / \mathrm{L})$ & $1.923(0.739-5.007)$ & 0.180 & - & - \\
\hline Y-GT $(\geq 50 \mathrm{U} / \mathrm{L}$ vs. $<50 \mathrm{U} / \mathrm{L})$ & $1.444(0.567-3.677)$ & 0.440 & - & - \\
\hline $\mathrm{Cr}(>80 \mu \mathrm{mol} / \mathrm{L}$ vs. $\leq 80 \mu \mathrm{mol} / \mathrm{L})$ & $1.195(0.456-3.129)$ & 0.717 & - & - \\
\hline
\end{tabular}

WBC White blood cell, PLT Platelet, CRP C-reactive protein, PCT Procalcitonin, IL-6 Interleukin-6, SaO 2 Oxygen saturation, TBIL Total bilirubin, ALT Alanine aminotransferase, AST Aspartate aminotransferase, LDH Lactate dehydrogenase, $\gamma$-GT $\gamma$-glutamyl transpeptadase, $\mathrm{Cr} C \mathrm{Creatinine,} \mathrm{HR}$ Hazard ratio, 95\% CI 95\% confidence interval 


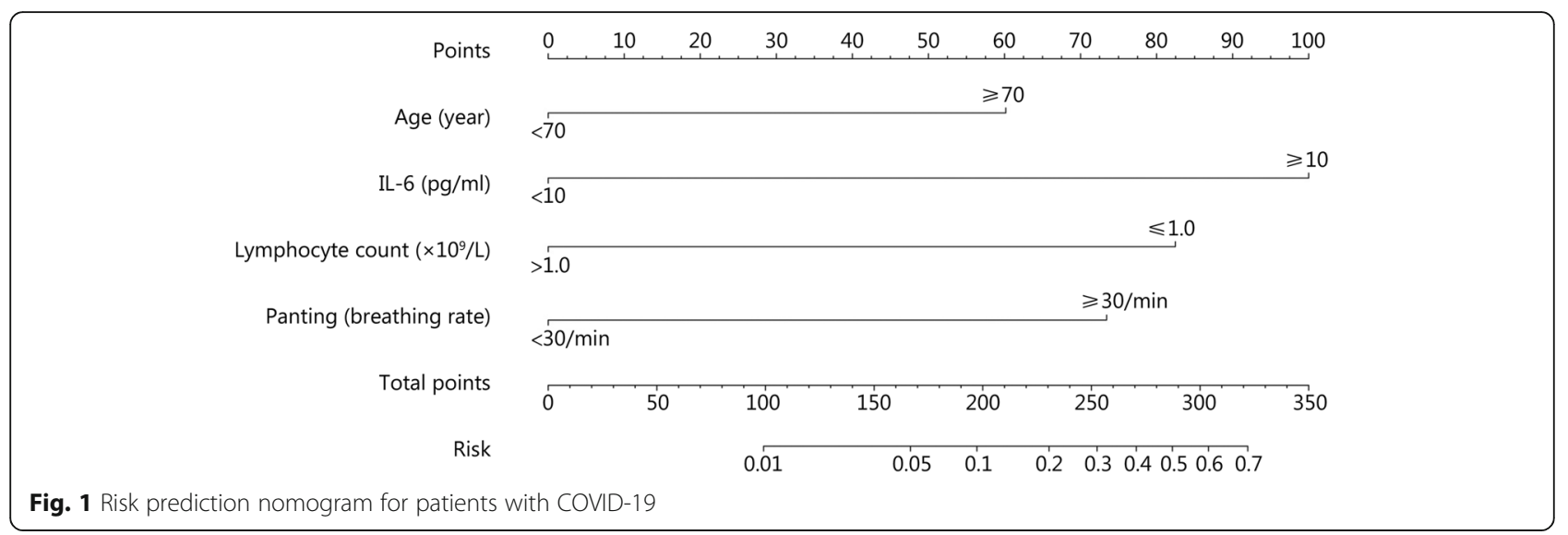

associated with worse survival without significance [18]. Our study showed that a high level of IL-6 was a predictor of death in severe COVID-19 patients. Additionally, the survival curve showed that the outcome was better in patients with tocilizumab than in patients without tocilizumab in the training cohort. Nonetheless, no significant difference was found. Similar results were also found in validation cohort 1 and validation cohort 2 . The reason for this result may be attributable to the small sample size. Although the previous study has shown that tocilizumab can reduce mortality, highquality studies are still needed to verify the effectiveness of tocilizumab on the survival of patients with severe COVID-19 [29].

Increasing respiratory rate is an important clinical feature of acute respiratory distress syndrome (ARDS), which is a major cause of death in severe COVID-19 patients $[8,17,30]$. A previous study showed that a respiratory rate $\geq 24 / \mathrm{min}$ was a risk factor for death in the univariate analysis [18], whereas no significance was found after the multivariate regression analysis. Our multivariate regression analysis clarified that a respiratory rate $\geq 30 /$ min was a predictor of death. For patients with increasing respiratory rates, especially those with respiratory rate $\geq 30 / \mathrm{min}$, it is necessary for physicians to be aware of the potential progression of ARDS.

Many previous studies have shown that comorbidity was significantly associated with high mortality rate and disease progression [24, 31]. Nevertheless, in this study, the significance of comorbidity was only indicated in the univariate analysis, but not in the multivariate regression analysis, which may be ascribed to different patients enrolled in these studies. All the patients included in this study had severe COVID-19, and the proportion of comorbidities was approximately $70 \%$, which was significantly higher than those in other studies.

Previous studies have shown several prediction models with different parameters [1, 24, 31, 32]. Compared with other studies, the predictive effect of age, panting, and lymphopenia has been described in previous reports, while the main feature of this study is the analysis of the prognostic value of IL- 6 in severe COVID-19 patients for the first time. IL-6 plays an important role in the pathophysiological changes of severe cases. However, the prediction value of IL-6 was not shown in other prediction models. In addition, our study also indicated that
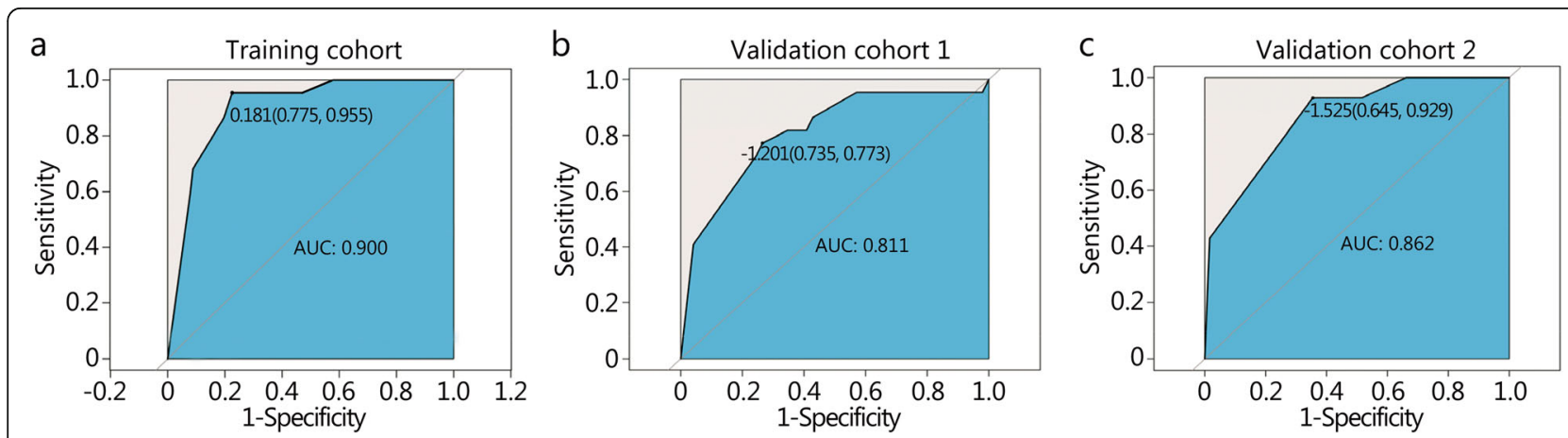

Fig. 2 The receiver operating characteristic (ROC) curves of the nomogram in the training cohort $\mathbf{a}$, validation cohort $1 \mathbf{b}$, and validation cohort 2 c 

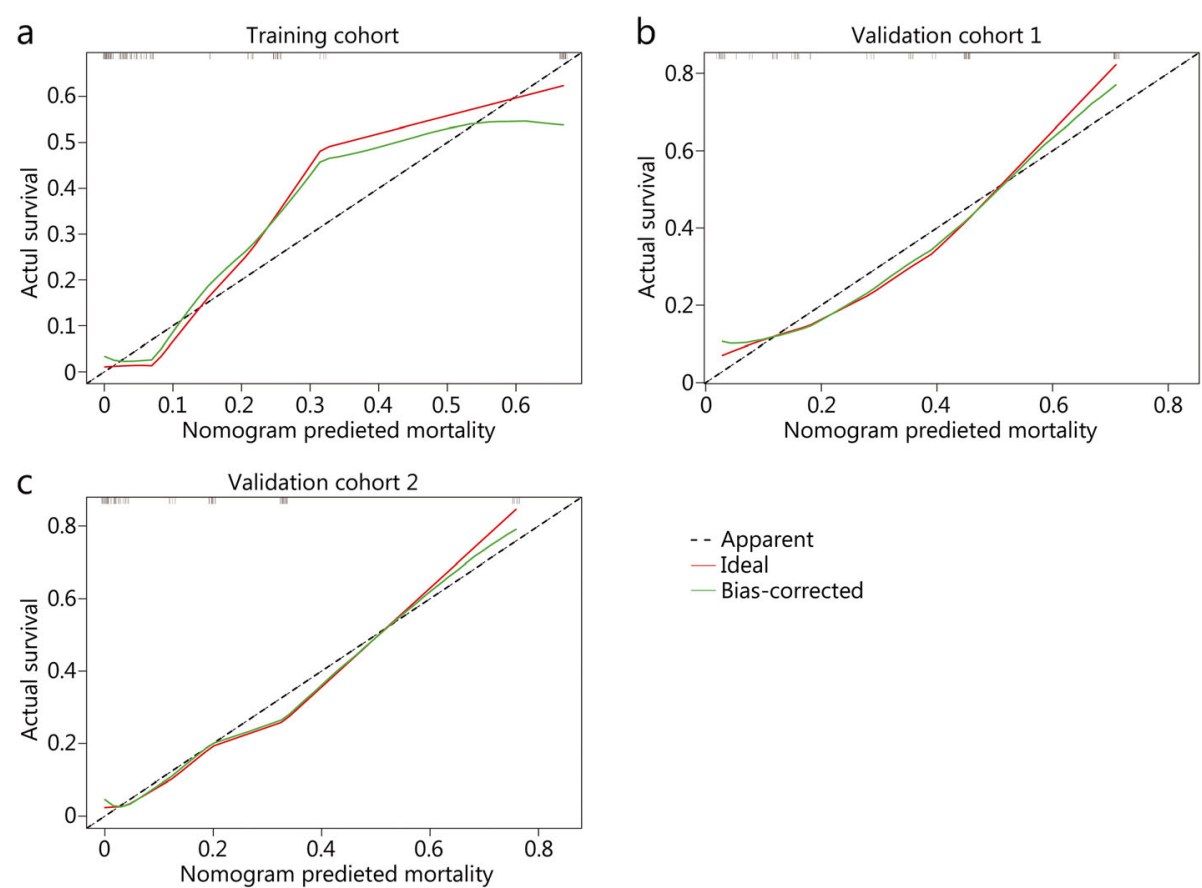

- Ideal

- Bias-corrected

Fig. 3 The calibration curves of the nomogram in the training cohort $\mathbf{a}$, validation cohort $1 \mathbf{b}$, and validation cohort $2 \mathbf{c}$
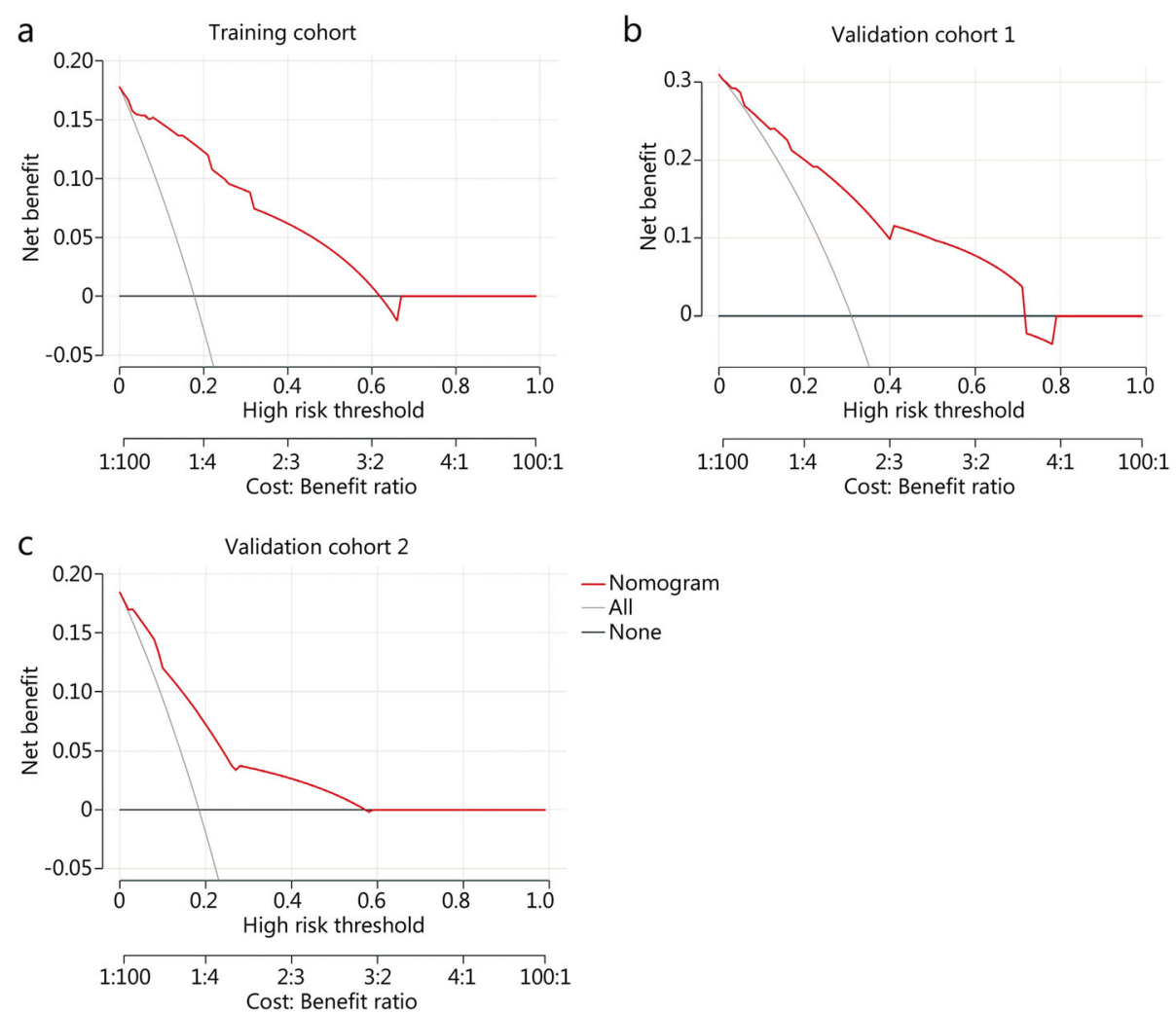

Fig. 4 Decision curve analysis of the nomogram of patients with COVID-19. DCA compares the net benefits of three scenarios in predicting the risk of mortality: A perfect prediction model (grey line), screen none (horizontal solid black line), and screen based on the nomogram (ride line). The DCA curves were depicted in the training cohort $\mathbf{a}$, validation cohort $1 \mathbf{b}$, and validation cohort $2 \mathbf{c}$. 
tocilizumab, a monoclonal antibody against the IL-6 receptor, may improve the prognosis of severe COVID-19 patients with the high level of IL-6.

Our study has some limitations. First, this is a retrospective study, and there may be potential biases in the selection of patients. Second, the sample size of the study was relatively small, and the results need to be further validated in a larger cohort.

\section{Conclusion}

This study firstly developed a nomogram for predicting fatal outcomes in the severe COVID-19 patients. The four predictors included in the model are easy to obtain. The prediction risk of the model indicated a good consistency with the observed one. Hence, this nomogram may be conducive to more effective treatment to reduce the mortality of those severe cases at high risk of death.

\section{Abbreviations \\ COVID-19: Coronavirus disease 2019; SARS-CoV-2: Severe acute respiratory syndrome coronavirus 2; APACHE II: Acute Physiology and Chronic Health Evaluation II; CK: Creatine kinase; CRP: C-reactive protein; IgA: Immunoglobulin A; qRT-PCR: Quantitative real-time reverse transcriptase- polymerase chain reaction; CT: Computed tomography; WBC: White blood cell; PLT: Platelet; PCT: Procalcitonin; IL-6: Interleukin-6; $\mathrm{SaO}_{2}$ : Oxygen saturation; TBIL: Total bilirubin; ALT: Alanine aminotransferase; AST: Aspartate aminotransferase; LDH: Lactate dehydrogenase; $\gamma$-GT: $\gamma$-glutamyl transpeptadase; Cr: Creatinine; HR: Hazard ratio; 95\% Cl: 95\% Confidence interval; ARDS: Acute respiratory distress syndrome.}

\section{Supplementary Information}

The online version contains supplementary material available at https://doi. org/10.1186/s40779-021-00315-6.

\section{Additional file 1: Supplemental Figure 1 Selection of the study population.}

Additional file 2: Supplemental Figure 2 Survival curves of severe COVID-19 patients with the high level of IL-6 receiving tocilizumab and not receiving tocilizumab treatment. a The survival curve of severe COVID-19 patients with the high level of IL-6 receiving tocilizumab and not receiving tocilizumab treatment in the training cohort $(P=0.105)$. $\mathbf{b}$ The survival curve of severe COVID-19 patients with the high level of IL-6 receiving tocilizumab and not receiving tocilizumab treatment in the validation cohort $1(P=0.133)$. c The survival curve of severe COVID-19 patients with the high level of $I L-6$ receiving tocilizumab and not receiving tocilizumab treatment in the validation cohort $2(P=0.210)$.

Additional file 3: Supplemental Table 1 Comparison of Baseline characteristics between severe patients and non-severe patients n(\%). WBC. White blood cell; PLT. Platelet; CRP. C-reactive protein; PCT. Procalcitonin; IL6. Interleukin-6; $\mathrm{SaO}_{2}$. Oxygen saturation; TBIL. Total bilirubin; ALT. Alanine aminotransferase; AST. Aspartate aminotransferase; LDH. Lactate dehydrogenase; $\gamma$-GT. $\gamma$-glutamyl transpeptadase; $C$ r. Creatinine; $C$. Computed tomography. Supplemental Table $\mathbf{2}$ Baseline characteristics of the patients $[n(\%)] .{ }^{a}$ Ages are shown as median (range). WBC. White blood cell; PLT. Platelet; CRP. C-reactive protein; PCT. Procalcitonin; IL-6. Interleukin-6; $\mathrm{SaO}_{2}$. Oxygen saturation; TBIL. Total bilirubin; ALT. Alanine aminotransferase; AST. Aspartate aminotransferase; LDH. Lactate dehydrogenase; $\gamma$-GT. $\gamma$-glutamyl transpeptadase; Cr. Creatinine; CT. Computed tomography

\section{Acknowledgements}

We would like to thank the staff of the Department of Critical Care Medicine of Huoshen Mountain Hospital, Wuhan Hubei Province, who contributed to this study by collecting the required data in the hospital data system.

\section{Authors' contributions}

$Y Y, X F Z, J H$, and CC designed this study; YZ, WH, LHZ, QG, XXH, LJF, YZ, and $Y Q C$ collected the data; $Y Y$ and $J H$ were responsible for the statistical analysis; YY wrote the draft; XFZ, YQC, and HJZ revised this draft; ZJL finalized this manuscript. The authors read and approved the final manuscript.

\section{Funding}

This work was supported by grants from the National Natural Science Foundation of China (81502416) to Dr. Yun Yang.

Availability of data and materials

The patient level data has been uploaded to the Figshare database. Dataset. https://doi.org/10.6084/m9.figshare.12866060.v1.

\section{Declaration}

\section{Ethics approval and consent to participate}

The study was approved by the Ethics Committee of all the study centers. Written informed consent was waived by the Ethics Commission of each hospital for emerging infectious.

\section{Consent for publication}

No individual participant data is reported that would require consent to publish from the participant (or legal parent or guardian for children).

\section{Competing interests}

The authors declare that they have no competing interests.

\section{Author details}

${ }^{1}$ The Third Affiliated Hospital of Second Military Medical University, 225 Changhai Road, Shanghai 200438, China. ${ }^{2}$ The Guanggu Branch of the Women and Children's Hospital of Hubei Province, Wuhan 430070, China. ${ }^{3}$ The First Affiliated Hospital of Second Military Medical University, Shanghai 200438, China. ${ }^{4} 904$ Hospital of PLA Joint Logistic Support Force, Wuxi 215000, Jiangsu, China. ${ }^{5}$ Tongji Taikang Hospital, Wuhan 430050, China. ${ }^{6} 924$ Hospital of PLA Joint Logistic Support Force, Guilin 541002, Guangxi, China.

${ }^{7}$ Huoshen Mountain Hospital, Wuhan 430113, China.

Received: 6 July 2020 Accepted: 8 March 2021

Published online: 17 March 2021

\section{References}

1. Gong J, Ou J, Qiu X, Jie Y, Chen Y, Yuan L, Cao J, Tan M, Xu W, Zheng F, Shi $Y, \mathrm{Hu} B$, et al. A tool to early predict severe corona virus disease 2019 (COVID-19): a multicenter study using the risk nomogram in Wuhan and Guangdong, China. Clin Infect Dis. 2020;71(15):833-40. https://doi.org/10.1 093/cid/ciaa443.

2. Guan WJ, Ni ZY, Hu Y, Liang WH, Qu CQ, He JX, et al. Clinical characteristics of 2019 novel coronavirus infection in China. medRxiv. 2020:02.06.20020974.

3. Wang D, Hu B, Hu C, Zhu F, Liu X, Zhang J, Wang B, Xiang H, Cheng Z, Xiong Y, Zhao Y, Li Y, Wang X, Peng Z, et al. Clinical characteristics of 138 hospitalized patients with 2019 novel coronavirus-infected pneumonia in Wuhan, China. JAMA. 2020;323(11):1061-9. https://doi.org/10.1001/jama.202 0.1585

4. Menzella F, Fontana M, Salvarani C, Massari M, Ruggiero P, Chiara Scelfo C, et al. Efficacy of tocilizumab in patients with COVID-19 ARDS undergoing noninvasive ventilation. Crit Care. 2020;24(1):589. https://doi.org/10.1186/s13 054-020-03306-6.

5. Chen NS, Zhou M, Dong X, Qu JM, Gong FY, Han Y, Qiu Y, Wang J, Liu Y, Wei $Y$, Xia J', Yu T, Zhang X, Zhang L, et al. Epidemiological and clinical characteristics of 99 cases of 2019 novel coronavirus pneumonia in Wuhan, China: a descriptive study. Lancet. 2020;395(10223):507-13. https://doi.org/1 0.1016/S0140-6736(20)30211-7.

6. Huang $C L$, Wang $Y M$, Li XW, Ren LL, Zhao JP, Hu Y, Zhang L, Fan G, Xu J, Gu X, Cheng Z, Yu T, Xia J, Wei Y, Wu W, Xie X, Yin W, Li H, Liu M, Xiao Y, Gao H, Guo L, Xie J, Wang G, Jiang R, Gao Z, Jin Q, Wang J, Cao B, et al. Clinical features of patients infected with 2019 novel coronavirus in Wuhan, China. Lancet. 2020;395(10223):497-506. https://doi.org/10.1016/S0140-673 6(20)30183-5. 
7. Bhatraju PK, Ghassemieh BJ, Nichols M, Kim R, Jerome KR, Nalla AK, Greninger AL, Pipavath S, Wurfel MM, Evans L, Kritek PA, West TE, Luks A, Gerbino A, Dale CR, Goldman JD, O'Mahony S, Mikacenic C, et al. COVID-19 in critically ill patients in the Seattle region - case series. N Engl J Med. 2020; 382(21):2012-22. https://doi.org/10.1056/NEJMoa2004500.

8. Yang XB, Yu Y, Xu JQ, Shu HQ, Xia JA, Liu H, et al. Clinical course and outcomes of critically ill patients with SARS-CoV-2 pneumonia in Wuhan, China: a single-centered, retrospective, observational study. Lancet Respir Med. 2020;8(5):475-81. https://doi.org/10.1016/S2213-2600(20)30079-5.

9. Zhang GM, Zhang J, Wang BW, Zhu XL, Wang Q, Qiu SM, et al. Analysis of clinical characteristics and laboratory findings of 95 cases of 2019 novel coronavirus pneumonia in Wuhan, China: a retrospective analysis. Respir Res. 2020;21(1):74. https://doi.org/10.1186/s12931-020-01338-8.

10. Xie JJ, Shi D, Bao MY, Bao MY, Hu XY, Wu WR, et al. A predictive nomogram for predicting improved clinical outcome probability in patients with COVID-19 in Zhejiang Province, China. Engineering (Beijing). 2020. https:// doi.org/10.1016/j.eng.2020.05.014, A Predictive Nomogram for Predicting Improved Clinical Outcome Probability in Patients with COVID-19 in Zhejiang Province, China.

11. World Health Organization. Clinical management of severe acute respiratory infection when novel coronavirus ( $\mathrm{nCoV}$ ) infection is suspected: Interim guidance, January 28, 2020. Available from: https://apps.who.int/iris/ha ndle/10665/330893 Accessed 31 Jan 2020.

12. National Health Commission (NHC) of the PRC and National Administration of Traditional Chinese Medicine of the PRC. Guidance for corona virus disease 2019: Prevention, control, diagnosis and management. China: Peoples Medical Publishing House; 2020.

13. World Health Organization. Clinical management of severe acute respiratory infection (SARI) when COVID-19 disease is suspected: Interim guidance, 13 March 2020. World health organization. Available from: https://appswhoint/ iris/handle/10665/331446 Accessed 31 May 2020.

14. World Health Organization. Laboratory testing for 2019 novel coronavirus (2019-nCoV) in suspected human cases: Interim guidance, 19 March 2020. Available from: https://www.who.int/publications/i/item/10665-331501 Accessed 19 March 2020.

15. Corman VM, Landt O, Kaiser M, Molenkamp R, Meijer A, Chu DK, et al. Detection of 2019 novel coronavirus (2019-nCoV) by real-time RT-PCR. Euro Surveill. 2020;25(3):2000045.

16. Chen HJ, Guo JJ, Wang C, Luo F, Yu XC, Zhang W, Li J, Zhao D, Xu D, Gong Q, Liao J, Yang H, Hou W, Zhang $Y$, et al. Clinical characteristics and intrauterine vertical transmission potential of COVID-19 infection in nine pregnant women: a retrospective review of medical records. Lancet. 2020; 395(10226):809-15. https://doi.org/10.1016/S0140-6736(20)30360-3.

17. Chen T, Wu D, Chen HL, Yan WM, Yang DL, Chen G, et al. Clinical characteristics of 113 deceased patients with coronavirus disease 2019: retrospective study. BMJ. 2020;368:m1091.

18. Zhou F, Yu T, Du RH, Fan GH, Liu Y, Liu ZB, et al. Clinical course and risk factors for mortality of adult inpatients with COVID-19 in Wuhan, China: a retrospective cohort study. Lancet. 2020;395(10229):1054-62. https://doi. org/10.1016/S0140-6736(20)30566-3.

19. Guo YR, Cao QD, Hong ZS, Tan YY, Chen SD, Jin HJ, Tan KS, Wang DY, Yan $Y$, et al. The origin, transmission and clinical therapies on coronavirus disease 2019 (COVID-19) outbreak - an update on the status. Mil Med Res. 2020;7(1):11. https://doi.org/10.1186/s40779-020-00240-0.

20. Li LZ, Zhang BH, He B, Gong ZJ, Chen XB. Critical patients with coronavirus disease 2019: risk factors and outcome nomogram. J Inf Secur. 2020;80(6): e37-8.

21. Wang F, Nie JY, Wang HZ, Zhao Q, Xiong Y, Deng LP, Song S, Ma Z, Mo P, Zhang $Y$, et al. Characteristics of peripheral lymphocyte subset alteration in COVID-19 pneumonia. J Infect Dis. 2020;221(11):1762-9. https://doi.org/10.1 093/infdis/jiaa150.

22. Qin C, Zhou LQ, Hu ZW, Zhang SQ, Yang S, Tao Y, Xie C, Ma K, Shang K, Wang W, Tian DS, et al. Dysregulation of immune response in patients with COVID-19 in Wuhan, China. Clin Infect Dis. 2020;71(15):762-8. https://doi. org/10.1093/cid/ciaa248.

23. Terpos E, Ntanasis-Stathopoulos I, Elalamy I, Kastritis E, Sergentanis TN, Politou M, Psaltopoulou T, Gerotziafas G, Dimopoulos MA, et al. Hematological findings and complications of COVID-19. Am J Hematol. 2020;95(7):834-47. https://doi.org/10.1002/ajh.25829.

24. Ji D, Zhang DW, Xu J, Chen Z, Yang TN, Zhao P, Chen G, Cheng G, Wang Y, Bi J, Tan L, Lau G, Qin E, et al. Prediction for progression risk in patients with
COVID-19 pneumonia: the CALL score. Clin Infect Dis. 2020;71(6):1393-9. https://doi.org/10.1093/cid/ciaa414.

25. Ye Q, Wang BL, Mao JH. The pathogenesis and treatment of the 'cytokine storm' in COVID-19. J Inf Secur. 2020;80(6):607-13.

26. Mehta P, McAuley DF, Brown M, Sanchez E, Tattersall RS, Manson JJ, HLH Across Speciality Collaboration, UK, et al. COVID-19: consider cytokine storm syndromes and immunosuppression. Lancet. 2020;395(10229):1033-4. https://doi.org/10.1016/S0140-6736(20)30628-0.

27. Zhang C, Wu Z, Li JW, Zhao H, Wang GQ. Cytokine release syndrome in severe COVID-19: Interleukin-6 receptor antagonist tocilizumab may be the key to reduce mortality. Int J Antimicrob Agents. 2020;55(5):105954. https:// doi.org/10.1016/j.ijantimicag.2020.105954.

28. Zhang SY, Li L, Shen AZ, Chen YW, Qi ZG. Rational use of tocilizumab in the treatment of novel coronavirus pneumonia. Clin Drug Investig. 2020;40(6): 511-8. https://doi.org/10.1007/s40261-020-00917-3.

29. Jin $Y H$, Zhan QY, Peng ZY, Ren $X Q$, Yin XT, Cai L, et al. Chemoprophylaxis, diagnosis, treatments, and discharge management of COVID-19: an evidence-based clinical practice guideline (updated version). Mil Med Res. 2020;7(1):41. https://doi.org/10.1186/s40779-020-00270-8.

30. Yang F, Shi SB, Zhu JL, Shi JZ, Dai K, Chen XB. Analysis of 92 deceased patients with COVID-19. J Med Virol. 2020;92(11):2511-5. https://doi.org/10.1 002/jmv.25891.

31. Chen RC, Liang WH, Jiang M, Guan WJ, Zhan C, Wang T, Tang C, Sang L, Liu J, Ni Z, Hu Y, Liu L, Shan H, Lei C, Peng Y, Wei L, Liu Y, Hu Y, Peng P, Wang J, Liu J, Chen Z, Li G, Zheng Z, Qiu S, Luo J, Ye C, Zhu S, Liu X, Cheng L, Ye F, Zheng J, Zhang N, Li Y, He J, Li S, Zhong N, Medical Treatment Expert Group for COVID-19, et al. Risk factors of fatal outcome in hospitalized subjects with coronavirus disease 2019 from a nationwide analysis in China. Chest. 2020;158(1):97-105. https://doi.org/10.1016/j.chest.2020.04.010.

32. Zhang $S$, Guo MF, Duan LM, Wu F, Hu GR, Wang ZH, Huang Q, Liao T, Xu J, Ma Y, Lv Z, Xiao W, Zhao Z, Tan X, Meng D, Zhang S, Zhou E, Yin Z, Geng W, Wang $X$, Zhang J, Chen J, Zhang Y, Jin Y, et al. Development and validation of a risk factor-based system to predict short-term survival in adult hospitalized patients with COVID-19: a multicenter, retrospective, cohort study. Crit Care. 2020;24(1):438. https://doi.org/10.1186/s13054-02003123-x.

Ready to submit your research? Choose BMC and benefit from

- fast, convenient online submission

- thorough peer review by experienced researchers in your field

- rapid publication on acceptance

- support for research data, including large and complex data types

- gold Open Access which fosters wider collaboration and increased citations

- maximum visibility for your research: over $100 \mathrm{M}$ website views per year

At $\mathrm{BMC}$, research is always in progress.

Learn more biomedcentral.com/submissions 